\title{
microRNA-34 family and treatment of cancers with mutant or wild-type p53 (Review)
}

\author{
MAY Y.W. WONG ${ }^{1,2}$, YAN YU ${ }^{1}$, WILLIAM R. WALSH ${ }^{1}$ and JIA-LIN YANG ${ }^{2}$ \\ ${ }^{1}$ Surgical and Orthopaedics Research Laboratories and ${ }^{2}$ Surgical Oncology Research Group, \\ Prince of Wales Clinical School, Faculty of Medicine, University of New South Wales, Sydney, NSW, Australia
}

Received December 16, 2010; Accepted February 8, 2011

DOI: $10.3892 /$ ijo.2011.970

\begin{abstract}
In the last decade, microRNAs (miRNAs; small noncoding RNA molecules) as post-transcriptional regulators have been a hotspot in research for their involvement in biological processes and tumour development. However, there have been few reviews focusing on a single miRNA family. The dysregulation of miRNAs appears to play a crucial role in cancer pathogenesis where they exert their effect as oncogenes or as tumour suppressors. This review summarises current studies on the dysregulation of the microRNA-34 (miR-34) family in different types of cancers and its role in the p53 network. The structure of the miR-34 family members includes p53-binding sites reflecting their function as tumour suppressors downstream of the p53 pathway. miR-34 dysregulation occurs in cancers, including several epithelial cancers, melanomas, neuroblastomas, leukemias and sarcomas, in the presence or absence of the p53 mutation. For these cancers, functional restoration of miR-34 is a useful novel therapy. As evidenced from preclinical and clinical studies, the miR-34 family plays an important role in the treatment of miR-34dysregulated cancers with mutant or wild-type p53. This review will have a potential impact in the clinical treatment of p53-mutant and/or miR-34-dysregulated cancers using a miR-34 restoration approach.
\end{abstract}

\section{Contents}

1. Introduction

2. miR-34 structure and the p53-binding site

3. miR-34 family in normal function

4. p53 mutation and the role of miR-34 in cancer

5. Therapeutic potential of miR-34

6. Conclusion

Correspondence to: Dr Jia-Lin Yang, Oncology Research Centre, Level 2 Clinical Sciences Building, Prince of Wales Hospital, Randwick, Sydney, NSW 2031, Australia

E-mail: j.yang@unsw.edu.au

Key words: miR-34, p53, microRNA, apoptosis, cancer therapy

\section{Introduction}

microRNAs (miRNAs) are small regulatory noncoding RNAs that repress gene expression at the post-transcriptional level in a sequence-specific manner. They play a crucial role in varying aspects of cell proliferation, differentiation and apoptosis (1). However, the vast number of miRNA genes, their varied expression patterns and the wealth of potential miRNA targets suggest that miRNAs are likely to be involved in an extended spectrum of human pathologies (2). Alterations in their expression have displayed correspondence with disease states in pathologic conditions such as Alzheimer's disease. Factors required for miRNA processing and/or function have also been involved in fragile X mental retardation (3) and DiGeorge syndrome (4). miRNA dysregulation is also associated with the initiation and development of cancer (5-7) as they are misexpressed in malignant tumours with respect to their normal tissue equivalents. Table I summarises the mechanisms in which this occurs. Calin et al demonstrated that greater than half of human miRNAs map to fragile or cancer-associated genomic regions that are susceptible to deletions, amplifications or recombination (8). Such locations suggest that various miRNAs are involved in tumourigenesis (8-10).

miRNAs cause either tumour suppression or tumour development. One class includes oncogenes, also known as oncomirs, whose expression is upregulated in tumours. They catalyse tumour development by negatively inhibiting tumoursuppressor genes. Conversely, miRNA expression may also be downregulated in cancerous cells. These types of miRNAs are considered tumour-suppressor genes which prevent tumour development by negatively inhibiting oncogenes.

Since the first miRNA was described in 1993 (11), many new miRNAs have been discovered (12-14), and currently a miRNA registry (http://www.sanger.ac.uk/software/rfam/) contains sequence data on more than 10,500 miRNAs. However, to date, a specific function has been assigned to just a few miRNAs.

miRNA-directed gene regulation is a rapidly emerging area of research and study, propelled by technological advancements in RNA-based methods including cloning and size-fractionated RNA strategies $(12,15,16)$. Highthroughput sequencing methods employing microarray hybridisation (17-23) and computational and bioinformatic prediction technologies (24-26) are significant in classifying particular miRNA signatures and uncovering regulatory 
Table I. Mechanisms of microRNA dysregulation.

Mechanisms

Aberrant transcription of the precursors by the epigenetic silencing of miRNA promoters through promoter methylation and histone acetylation;

Aberrant miRNA processing due to altered expression of miRNA biogenesis machinery;

Germline mutation of precursor miRNA molecules;

Rarely, point mutations in mature miRNAs or in target sequences that interfer with normal target recruitment.

Table II. Sequences of mature miR-34 family members. ${ }^{a}$

\begin{tabular}{lc}
\hline Molecule & Sequence \\
\hline hsa-miR-34a & 5'-UGGCAGUGUCUUAGCUGGUUGU-3' \\
hsa-miR-34b & 5'-CAAUCACUAACUCCACUGCCAU-3' \\
hsa-miR-34c & 5'-AGGCAGUGUAGUUAGCUGAUUGC-3'
\end{tabular}

${ }^{a}$ Sequence alignment of mature miR-34a, miR-34b and miR-34c molecules. The seed sequences at the 5'-UTRs in bold print are used to combine with targeted mRNAs for regulation purposes.

targets. Quantitative polymerase chain reaction (qPCR) validates miRNA expression profile $(27,28)$ and Northern blot analysis of gene expression (29). Recently, next generation sequencing technologies are being readily employed to achieve a more precise portrayal of miRNA expression profiles to enhance our understanding of the intricacy and methods of miRNA regulation $(30,31)$. Multiple reviews have summarised the mechanism of RNA interference (32-35), the biogenesis of miRNAs (36-38) and their role in gene regulation $(39,40)$. This review focuses on an individual miRNA family, miRNA-34 (miR-34), regarding its intrinsic link with p53.

This review aims to explore the research conducted on miR-34s for its role in the p53 network and relevant cancer treatment, specifically in regards to i) miR-34 structure and the p53-binding site, ii) miR-34 family in normal function, iii) p53 mutation and the role of miR-34 in cancer, and iv) the therapeutic potential of miR-34.

\section{2. miR-34 structure and the p53-binding site}

The miR-34 family shares some general characteristics with miRNAs. Normally, miRNAs are produced through a multistep progression involving two distinctive biogenetic pathways. During the maturation process, transcriptional and post-transcriptional levels are tightly monitored, ensuring accurate production. They are created from long primary transcripts that are developed in numerous steps to form cytoplasmic $\sim 22$-nucleotide mature miRNAs $(36,41,42)$ with the excision of a $30-\mathrm{kb}$ intron (43). The mature miRNA is then integrated into the miRNA-induced silencing complex (miRISC), which directs it to target sequences. Most miRNAs use their seed sequences on 5'-UTRs (Table II) to recognize their target sites located in 3'-UTRs by incomplete basepairing, resulting in mRNA destabilization or translational repression of the target genes $(44,45)$.

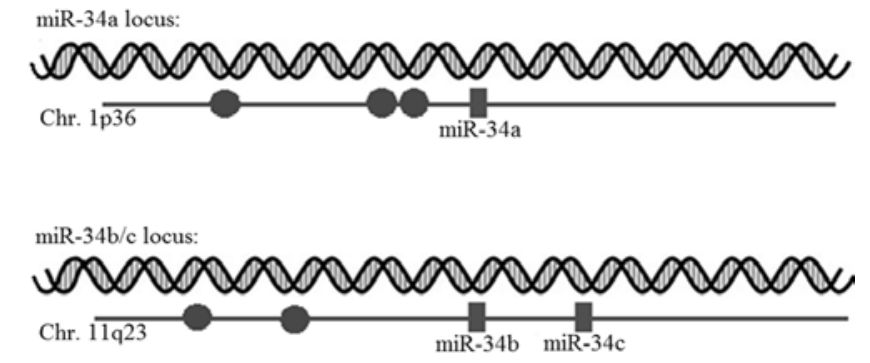

Figure 1. Structure of genomic loci of the human miR-34a and miR-34b/c genes. Rectangular box indicates miRNA hairpins; filled circles indicate p53-binding sites.

The miR-34 family includes three processed miRNAs (miR-34a, miR-34b, and miR-34c) that are encoded by two different genes $(46,47)$ (Fig. 1). miR-34a is encoded by an individual transcript while miR-34b and miR-34c share a common primary transcript. The gene encoding miR-34a is located on human chromosome 1p36, while miR-34b and miR-34c are co-transcribed from one transcription unit on chromosome 11q23. Animal studies have demonstrated that $\mathrm{miR}-34 \mathrm{~b} / \mathrm{c}$ is predominantly expressed in the lungs, and miR-34a is expressed in the brain, showing that they have tissue-specific functions (46). An expression analysis following individual transfection of each miR-34 showed that the affected mRNAs were almost indistinguishable. However, variations in the attractions for targets between the three miR-34 members occur. For instance, c-MYC is mainly regulated by miR-34b/c, evidenced by the enhanced complementarity between the miR-34b seed sequence and the seed-matching sequence in the c-MYC 3'-UTR, when evaluated against miR-34a (48). The miRNA-encoding sequences and short promoter proximal regions each house a consensus p53-binding site (47) anticipated to be within $30 \mathrm{~kb}$ of the precursor transcription units for all members of the miR-34 family. The proximity of the p53-binding site to both the miR-34a and miR-34b/c precursors has spurred the interest of many scientists.

\section{3. miR-34 family in normal function}

More than $60 \%$ of human protein-coding genes are conserved targets of miRNA (49-51). Thus, they have diverse biological functions, including developmental timing, signal transduction and tissue differentiation (52). The miR-34 family is an example of a single miRNA family which performs numerous biological functions (Table III and Table IV). 
Table III. Normal function of miR-34 family members.

Function

Role of miR-34s

Haematopoiesis and immunity

Stem cell biology

Skeletal and cardiac muscle

Nervous system
miRNA influences lineage selection and affects critical developmental checkpoints during haematopoiesis. Expression of miR-34a results in an incomplete block in B-cell development in murine bone marrow, mediated by blocked expression of the transcription factor, Foxp1, a known B-cell oncogene (66).

Silent information regulator 1 (SIRT1) gene, previously demonstrated to be involved in sustaining the undifferentiated phenotype in mouse embryonic stem cells (ESCs), is a direct target of miR-34 (67).

miR-34s are dramatically upregulated during normal human bronchial epithelial cell differentiation including ciliated and secretory cells within the mature airway epithelium (68).

During development, many miRNAs, including miR-34a, are expressed in neurons and show distinct expression patterns within the embryonic central nervous system, suggesting their role in brain formation and function (69-71). Expression of miR-34a is roughly 6-fold to 9-fold higher in the spinal cord, medulla oblongata, and pons compared to whole mouse brain (72).

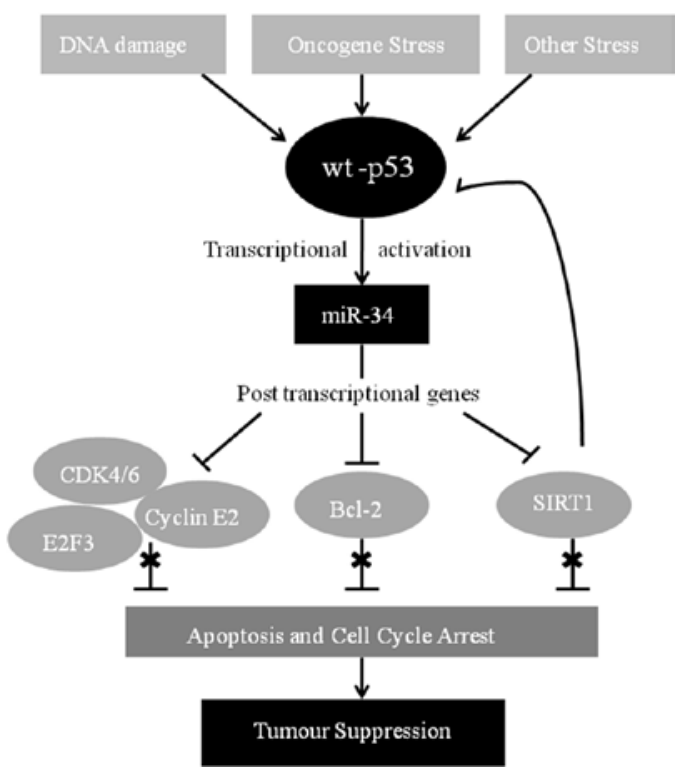

Figure 2. Molecular mechanisms in the p53-miR-34 network involved in regulating cell apoptosis. Briefly, wt-p53 activates miR-34 after DNA damage and/or cellular stress, which subsequently inhibits expression of anti-apoptotic genes and results in cell apoptosis and tumour suppression. Crosses reflect the downregulation of anti-apoptotic proteins by miR-34. Also shown is the regulation of SIRT1 by miR-34a as part of a positive feedback loop that leads to further activation of $\mathrm{p} 53$, once it has been activated. Abbreviations of anti-apoptotic proteins: CDK4/6, cyclin-dependent kinase 4/6; E2F3, E2F transcription factor 3; Bcl-2, B-cell lymphoma 2; SIRT1, silent information regulator 1 .

Regulation of cell cycle progression, apoptosis or senescence. The p53 protein is a transcription factor which blocks cell proliferation and stimulates cell death. It lies at the nexus of molecular pathways that monitor cellular disruptions and abnormal mitogenic activation (53). Cellular senescence and apoptosis, DNA-damaging agents, oxidative stress, and activation of oncogenes can all cause double-stranded breaks which stimulate ATM kinases and consequently phosphorylate p53 (46) (Fig. 2). p53 orchestrates such responses by directly activating miR-34a and subsequent key genes through binding

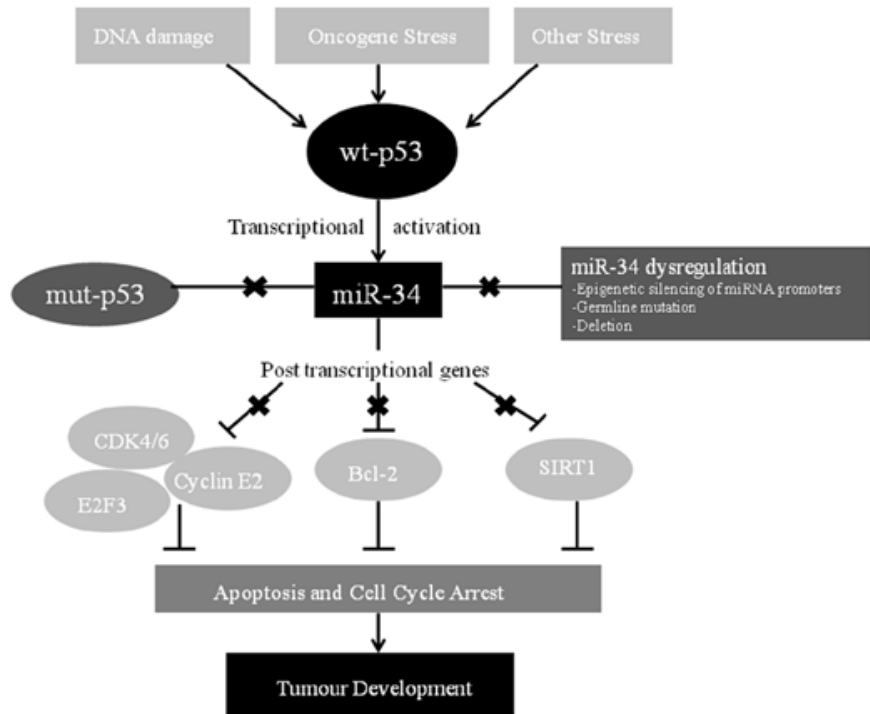

Figure 3. Abnormal regulation of the p53-miR-34 network causing cell proliferation and tumourigenesis. Briefly, the function of miR-34 is lower in the presence of mutant $\mathrm{p} 53$ and/or miR-34 dysregulation. Overexpression of anti-apoptotic genes and proteins result in cell proliferation and tumour development. Large crosses indicate sites of abnormality in the downstream pathway. Abbreviations of anti-apoptotic proteins as in Fig. 2 legend.

two repeats of the DNA sequence 5'-PuPuPuC(A/T)(T/A) GPyPyPy-3' (54). The p53 gene encodes effector proteins that induce cellular processes: p21 (G1-arrest), 14-3-3 $\sigma$ (G2-arrest) and Puma (apoptosis) (55). miR-34a is the most significantly induced miRNA which acts as a post-transcriptional target of p53 (46). It controls the crucial tumour suppressive effects of p53 through a context-dependent induction of growth arrest, apoptosis or senescence (56-58) being partly responsible for the downregulation of anti-apoptotic proteins (55).

\section{4. p53 mutation and the role of miR-34 in cancer}

p53 is a tumour suppressor which needs to be disabled or disrupted for most types of cancers to differentiate and proliferate (59). As such, mutations in the p53 pathway are 


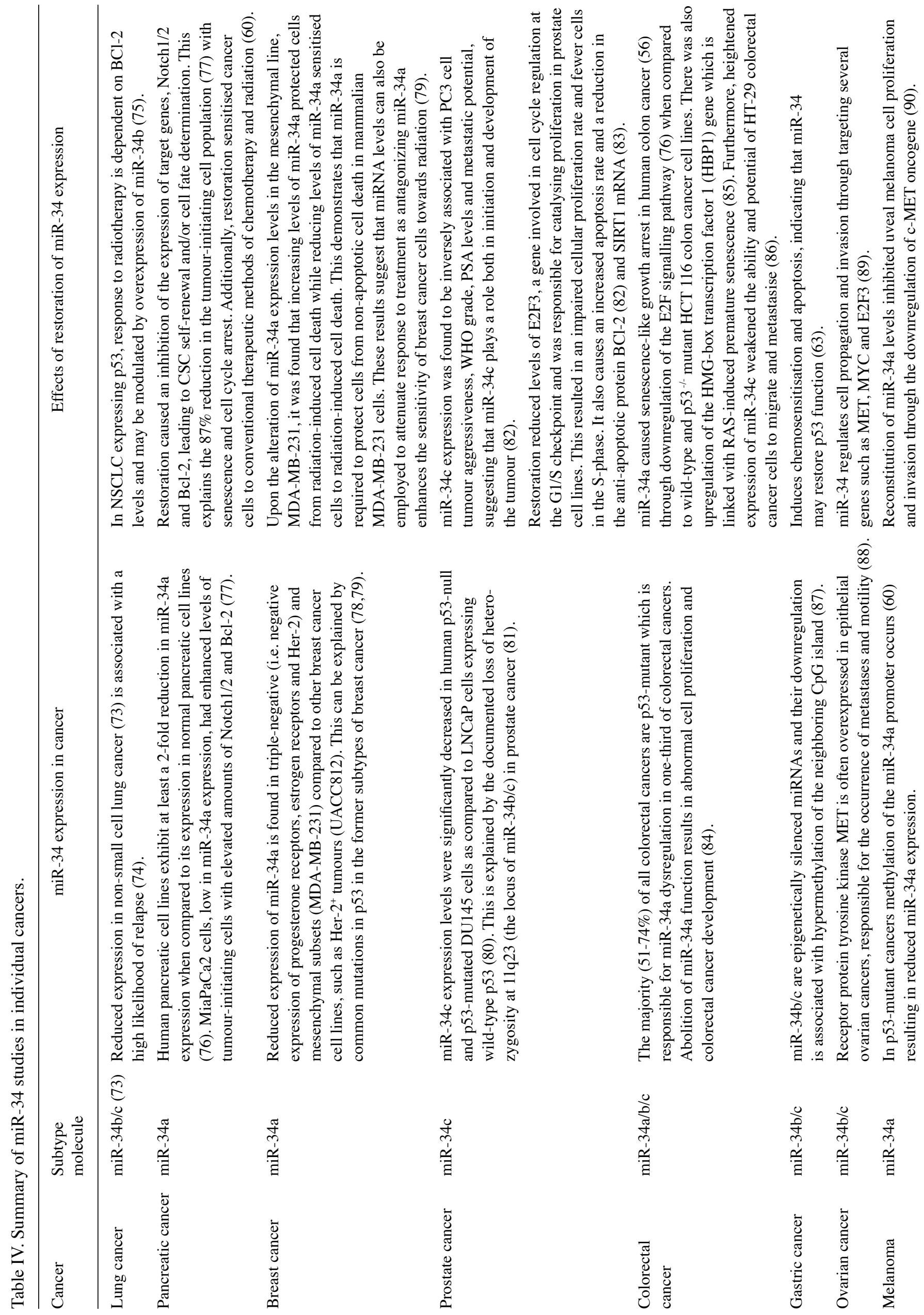




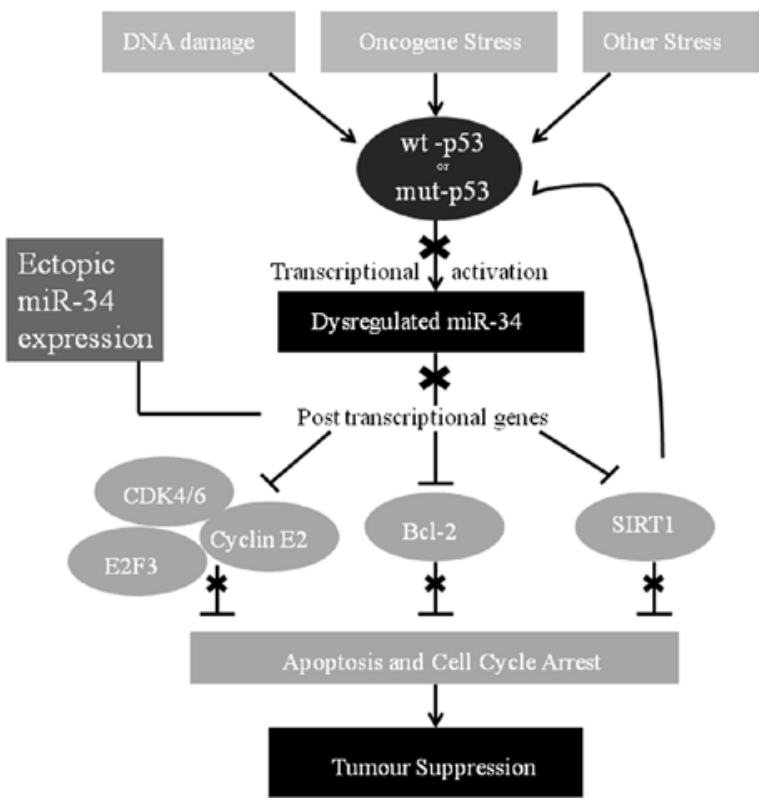

Figure 4. Treatment of p53-mutant or miR34-dysregulated cancer by ectopic miR-34. Briefly, the function of miR-34 is reduced in the presence of mutant p53 and/or miR-34 dysregulation. Delivery of ectopic miR-34 recovers its function and results in cell apoptosis and tumour suppression via inhibition of anti-apoptotic genes. Small crosses reflect the downregulation of antiapoptotic proteins by miR-34. Large crosses indicate sites of abnormality in the downstream pathway. Abbreviations of anti-apoptotic proteins: CDK4/6, cyclin-dependent kinase 4/6; E2F3, E2F transcription factor 3; Bcl-2, B-cell lymphoma 2; SIRT1, silent information regulator 1.

found in almost all forms of cancers (55) (Fig. 3). p53 mutations have been linked with antagonistic tumour behaviour and poor clinical outcome (47). p53 maps to 1 p36 (the locus of miR-34a), a region of common loss in various cancer forms (47). Thus, comparatively low levels of miR-34s are observed in human tumours and cancer cell lines (60).

\section{Therapeutic potential of miR-34}

It is known that the expression levels of miR-34 are deficient in p53-mutant cancer cells. This explains the abundance of research surrounding 'miRNA replacement therapy', which focuses on the concept that the re-introduction of miRNAs suppressed in p53-mutant cancer cells reactivates cellular pathways that initiates a therapeutic response (61) (Fig. 4). This involves introducing synthetic miR-34 or miR-34 mimetics into pathological tissues in an effort to reinstate normal proliferation, apoptosis, and other cellular functions (62). Specifically, the restoration of miR-34 was discovered to reduce the amount of tumour-initiating cells, or cancer stem cells (CSCs) (63). CSCs are tumour cells persisting after chemotherapy that, in almost all cancers, prompt the regrowth of the tumour. Characteristically, these cells are resistant to conventional therapies. As such, cancer treatment should be targeted against both resting CSCs and proliferating cancer cells. A study found that ectopic expression of miR-34 induces cell cycle arrest in both human-primary and tumour-derived cell lines which is in line with the capacity of miR-34 to downregulate a set of genes promoting cell cycle progression (64). 


\section{Conclusion}

This review demonstrates that $\mathrm{p} 53$, a potent tumour suppressor, modulates levels of miRNAs, specifically miR-34s. The expression of miR-34s is robustly induced by DNA damage and oncogenic stress in a p53-dependent approach. When overexpressed, miR-34 causes apoptosis or cellular senescence, whereas reduction of miR-34 function attenuates p53-mediated cell death. These findings, in association with the concept that miR-34 is downregulated in several forms of human cancer, show that miRNAs affect tumourigenesis by acting within the boundaries of established tumour-suppressor pathways. As such, they hold an important function in the treatment of p53-mutant or wild-type p53 cancers with dysregulated miR-34s using a miR-34 restoration approach. The restoration of functional miR-34 stimulates chemosensitisation and apoptosis, suggesting that miR-34 may restore p53 function. This inhibits tumour development as a result of the direct control of downstream anti-apoptotic proteins. Thus, the restoration of the tumour suppressor miR-34 may provide a novel molecular therapy for p53-mutant cancers. This review will have a clinical impact on the treatment of p53-mutant and/or miR-34-dysregulated cancers using a miR-34 restoration approach. Clinical studies using miR-34a (65) are underway and may provide further information to clarify the safety and efficacy of this molecule.

\section{References}

1. Pekarik V: Design of shRNAs for RNAi - A lesson from pre-miRNA processing: possible clinical applications. Brain Res Bull 68: 115-120, 2005.

2. Perron $\mathrm{M}$ and Provost P: Protein components of the microRNA pathway and human diseases. Methods Mol Biol 487: 369-385, 2009.

3. Jin P, Zarnescu D, Ceman S, et al: Biochemical and genetic interaction between the fragile $\mathrm{X}$ mental retardation protein and the microRNA pathway. Nat Neurosci 7: 113-117, 2004.

4. Landthaler M, Yalcin A and Tuschl T: The human DiGeorge syndrome critical region gene 8 and its D. melanogaster homolog are required for miRNA biogenesis. Curr Biol 14: 2162-2167, 2004.

5. Trang P, Weidhaas J and Slack F: MicroRNAs as potential cancer therapeutics. Oncogene 27: S52-S57, 2009.

6. Chira P, Vareli K, Sainis I, Papandreou C and Briasoulis E: Alterations of microRNAs in solid cancers and their prognostic value. Cancers 2: 1328-1353, 2010.

7. Zhang B, Pan X, Cobb G and Anderson T: microRNAs as oncogenes and tumor suppressors. Dev Biol 302: 1-12, 2006.

8. Calin G, Sevignani C, Dumitru C, et al: Human microRNA genes are frequently located at fragile sites and genomic regions involved in cancers. Proc Natl Acad Sci USA 101: 2999-3004, 2004.

9. Cheng A, Byrom M, Shelton J and Ford L: Antisense inhibition of human miRNAs and indications for an involvement of miRNA in cell growth and apoptosis. Nucleic Acids Res 33: 1290-1297, 2005.

10. Tanno B, Cesi V, Vitali R, et al: Silencing of endogenous IGFBP-5 by microRNA interference affects proliferation, apoptosis and differentiation of neuroblastoma cells. Cell Death Differ 12: 213-223, 2005

11. Lee R, Feinbaum R and Ambros V: The C.elegans heterochronic gene lin-4 encodes small RNAs with antisense complementarity to lin-14. Cell 75: 843-854, 1993.

12. Lagos-Quintana M, Rauhut R, Lendeckel $\mathrm{W}$ and Tuschl T: Identification of novel genes coding for small expressed RNAs. Science 294: 853-858, 2001.

13. Lagos-Quintana M, Rauhut R, Meyer J, Borkhardt A and Tuschl T: New microRNAs from mouse and human. RNA 9: $175-179,2003$
14. Lagos-Quintana M, Rauhut R, Yalcin A, Meyer J, Lendeckel W and Tuschl T: Identification of tissue-specific microRNAs from mouse. Curr Biol 12: 735-739, 2002.

15. Lau N, Lim L, Weinstein E and Bartel D: An abundant class of tiny RNAs with probable regulatory roles in Caenorhabditis elegans. Science 294: 858-862, 2001.

16. Lee R and Ambros V: An extensive class of small RNAs in Caenorhabditis elegans. Science 294: 862-864, 2001.

17. Baskerville S and Bartel D: Microarray profiling of microRNAs reveals frequent coexpression with neighboring miRNAs and host genes. RNA 11: 241-247, 2005.

18. Calin G, Ferracin M, Cimmino A, et al: A microRNA signature associated with prognosis and progression in chronic lymphocytic leukemia. N Engl J Med 353: 1793-1801, 2005.

19. Iorio M, Ferracin M, Liu C, et al: microRNA gene expression deregulation in human breast cancer. Cancer Res 65: 7065-7070, 2005.

20. Liang R, Li W, Li Y, et al: An oligonucleotide microarray for microRNA expression analysis based on labeling RNA with quantum dot and nanogold probe. Nucleic Acids Res 33: e17, 2005.

21. Lu C, Tej S, Luo S, Haudenschild C, Meyers B and Green P: Elucidation of the small RNA component of the transcriptome. Science 309: 1567-1569, 2001.

22. Meyer S, Pfaff M and Ulbrich S: Normalization strategies for microRNA profiling experiments: a 'normal' way to a hidden layer of complexity? Biotechnol Lett 32: 1777-1788, 2010.

23. Margulies M, Egholm M, Altman W, et al: Genome sequencing in microfabricated high-density picolitre reactors. Nature 437: 376-380, 2005.

24. Lai E, Tomancak P, Williams R and Rubin G: Computational identification of Drosophila microRNA genes. Genome Biol 4: R42, 2003.

25. Li S, Pan C and Lin W: Bioinformatic discovery of microRNA precursors from human ESTs and introns. BMC Genomics 3: 164,2006

26. Nam J, Shin K, Han J, Lee Y, Kim V and Zhang B: Human microRNA prediction through a probabilistic co-learning model of sequence and structure. Nucleic Acids Res 33: 3570-3581, 2005.

27. Sugito $\mathrm{N}$, Ishiguro $\mathrm{H}$, Kuwabara $\mathrm{Y}$, et al: RNASEN regulates cell proliferation and affects survival in esophageal cancer patients. Clin Cancer Res 12: 7322-7328, 2006.

28. Schmittgen T, Jiang J, Liu Q and Yang L: A high-throughput method to monitor the expression of microRNA precursors. Nucleic Acids Res 32: e43, 2004.

29. Hayashita Y, Osada H, Tatematsu Y, et al: A polycistronic microRNA cluster, miR-17-92, is overexpressed in human lung cancers and enhances cell proliferation. Cancer Res 65: 9628-9632, 2005.

30. Lee L, Zhang S, Etheridge A, et al: Complexity of the microRNA repertoire revealed by next-generation sequencing. RNA 16: 2170-2180, 2010.

31. Riback J, Hatzigeorgiou A and Reczko M: Computational classification of microRNAs in next-generation sequencing data. Theor Chem Acc 125: 637-642, 2010.

32. Murchison E and Hannon G: miRNAs on the move: miRNA biogenesis and the RNAi machinery. Curr Opin Cell Biol 16: 223-229, 2004.

33. Deiters A: Small molecule modifiers of the microRNA and RNA interference pathway. AAPS J 12: 51-60, 2010.

34. Rossbach M: Small non-coding RNAs as novel therapeutics. Curr Mol Med 10: 361-368, 2010.

35. Sontheimer E: Assembly and function of RNA silencing complexes. Nat Rev Mol Cell Biol 6: 127-138, 2005.

36. Bartel D: MicroRNAs: genomics, biogenesis, mechanism, and function. Cell 116: 281-297, 2004.

37. Narry-Kim V: MicroRNA biogenesis: coordinated cropping and dicing. Nat Rev Mol Cell Biol 6: 376-385, 2005.

38. Tomari Y and Zamore P: MicroRNA biogenesis: drosha can't cut it without a partner. Curr Biol 15: R61-R64, 2005.

39. Hobert O: Gene regulation by transcription factors and microRNAs. Science 319: 1785-1786, 2008.

40. Nilsen T: Mechanisms of microRNA-mediated gene regulation in animal cells. Trends Genetics 23: 243-249, 2007.

41. Du T and Zamore P: microPrimer: the biogenesis and function of microRNA. Development 132: 4645-4652, 2005.

42. Zeng Y: Principles of micro-RNA production and maturation. Oncogene 25: 6156-6162, 2006. 
43. Raver-Shapira N, Marciano E, Meiri E, Spector Y, Rosenfeld N, Moskovits N, Bentwich Z and Oren M: Transcriptional activation of miR-34a contributes to p53-mediated apoptosis. Mol Cell 26: 741-743, 2007

44. He L and Hannon G: MicroRNAs: small RNAs with a big role in gene regulation. Nat Rev Genet 5: 522-531, 2004

45. Bushati N and Cohen SM: microRNA functions. Annu Rev Cell Dev Biol 23: 175-205, 2007.

46. Hermeking H: p53 enters the microRNA world. Cancer Cell 12: 414-418, 2007

47. He X, He L and Hannon G: The guardian's little helper: microRNAs in the p53 tumor suppressor network. Cancer Res 67: 11099-11101, 2007.

48. Leucci E, Cocco M, Onnis A, et al: MYC translocation-negative classical Burkitt lymphoma cases: an alternative pathogenetic mechanism involving miRNA deregulation. J Pathol 216 : 440-450, 2008

49. Friedman R, Farh K, Burge C and Bartel D: Most mammalian mRNAs are conserved targets of microRNAs. Genome Res 19 92-105, 2009.

50. Lewis B, Burge C and Bartel D: Conserved seed pairing, often flanked by adenosines, indicates that thousands of human genes are microRNA targets. Cell 120: 15-20, 2005.

51. Xie X, Lu J, Kulbokas E, et al: Systematic discovery of regulatory motifs in human promoters and 3' UTRs by comparison of several mammals. Nature 434: 338-345, 2005.

52. Hatfield S and Ruohola-Baker H: microRNA and stem cell function. Cell Tissue Res 331: 57-66, 2008.

53. Levine $\mathrm{A}, \mathrm{Hu} \mathrm{W}$ and Feng Z: The p53 pathway: what questions remain to be explored? Cell Death Differ 13: 1027-1036, 2006.

54. El-Deiry W, Kern S, Pietenpol J, Kinzler K and Vogelstein B: Definition of a consensus binding site for p53. Nat Genet 1: 45-49, 1992.

55. Hermeking H: The miR-34 family in cancer and apoptosis. Cell Death Differ 17: 193-199, 2010

56. Tazawa $H$, Tsuchiya $N$, Izumiya $M$ and Nakagama $H$ : Tumorsuppressive miR-34a induces senescence-like growth arrest through modulation of the E2F pathway in human colon cancer cells. Proc Natl Acad Sci USA 104: 15472-15477, 2007.

57. Venturini L, Battmer K, Castoldi M, et al: Expression of the miR-17-92 polycistron in chronic myeloid leukemia (CML) CD34+ cells. Blood 109: 4399-4405, 2007.

58. Welch C, Chen Y and Stallings R: microRNA-34a functions as a potential tumor suppressor by inducing apoptosis in neuroblastoma cells. Oncogene 26: 5017-5022, 2007.

59. Junttila M and Evan G: p53 - a Jack of all trades but master of none. Nat Rev Cancer 9: 821-829, 2009.

60. Lodygin D, Tarasov V, Epanchintsev A, et al: Inactivation of miR-34a by aberrant CpG methylation in multiple types of cancer. Cell Cycle 7: 2591-2600, 2008.

61. Wiggins J, Ruffino L, Kelnar K, et al: Development of a lung cancer therapeutic based on the tumor suppressor microRNA34. Cancer Res 70: 5923-5930, 2010.

62. Wahid F, Shehzad A, Khan T and Kim Y: microRNAs: synthesis, mechanism, function, and recent clinical trials. Biochim Biophys Acta 1803: 1231-1243, 2010.

63. Ji Q, Hao X, Meng Y, et al: Restoration of tumor suppressor miR-34 inhibits human p53-mutant gastric cancer tumorspheres. BMC Cancer 8: 266, 2008.

64. He L, He X, Lim L, et al: A microRNA component of the p53 tumour suppressor network. Nature 447: 1130-1134, 2007.

65. Zenz T, Häbe S, Denzel T, et al: Detailed analysis of p53 pathway defects in fludarabine-refractory chronic lymphocytic leukemia (CLL): dissecting the contribution of $17 \mathrm{p}$ deletion, TP53 mutation, p53-p21 dysfunction, and miR34a in a prospective clinical trial. Blood 114: 2589-2598, 2009

66. Rao D, O'Connell R, Chaudhuri A, Garcia-Flores Y, Geiger T, and Baltimore D: microRNA-34a perturbs B lymphocyte development by repressing the forkhead box transcription factor Foxp1. Immunity 33: 48-59, 2010.

67. Tarantino C, Paolella G, Cozzuto L, et al: miRNA 34a, 100, and 137 modulate differentiation of mouse embryonic stem cells. FASEB J 24: 3255-3263, 2010.

68. Blagev D, Zlock L, Lao A, et al: MiR34 family members are upregulated during airway epithelial cell differentiation. Am J Respir Crit Care Med 181: A6443, 2010.

69. Krichevsky A, King K, Donahue C, Khrapko K and Kosik K A microRNA array reveals extensive regulation of microRNAs during brain development. RNA 9: 1274-1281, 2003.
70. Miska EA, Alvarez-Saavedra E, Townsend M, et al: Microarray analysis of microRNA expression in the developing mammalian brain. Genome Biol 5: R68, 2004.

71. Sempere L, Freemantle S, Pitha-Rowe I, Moss E, Dmitrovsky E and Ambros V: Expression profiling of mammalian microRNAs uncovers a subset of brain-expressed microRNAs with possible roles in murine and human neuronal differentiation. Genome Biol 5: R13, 2004.

72. Bak M, Silahtaroglu A, Moller M, et al: MicroRNA expression in the adult mouse central nervous system. RNA 14: 432-444, 2008

73. Bommer G, Gerin I, Feng Y, et al: p53-mediated activation of miRNA34 candidate tumor-suppressor genes. Curr Biol 17: 1298-1307, 2007.

74. Gallardo E, Navarro A, Viñolas N, et al: miR-34a as a prognostic marker of relapse in surgically resected non-small cell lung cancer. Carcinogenesis 30: 1903-1909, 2009.

75. Silva J, Neves S, Gonçalves C, et al: Evaluation of the role of mir-34b in modulation of radioresistance in non-small cell lung cancer. BMC Proc 4: 11, 2010.

76. Chang T, Wentzel E, Kent O, et al: Transactivation of miR-34a by p53 broadly influences gene expression and promotes apoptosis. Mol Cell 26: 745-752, 2007

77. Ji Q, Hao X, Zhang M, et al: MicroRNA miR-34 inhibits human pancreatic cancer tumor-initiating cells. PLoS One 4: e6816, 2009.

78. Hui L, Zheng Y, Yan Y, Bargonetti J and Foster D: Mutant p53 in MDA-MB-231 breast cancer cells is stabilized by elevated phospholipase D activity and contributes to survival signals generated by phospholipase D. Oncogene 25: 7305-7310, 2006.

79. Kato M, Paranjape T, Ullrich R, et al: The mir-34 microRNA is required for the DNA damage response in vivo in C.elegans and in vitro in human breast cancer cells. Oncogene 28: 2419-2424, 2009.

80. Lu J, Getz G, Miska E, et al: MicroRNA expression profiles classify human cancers. Nature 435: 834-838, 2005.

81. Dahiya R, McCarville J, Lee C, et al: Deletion of chromosome $11 \mathrm{p} 15, \mathrm{p} 12, \mathrm{q} 22, \mathrm{q} 23-24$ loci in human prostate cancer. Int J Cancer 72: 283-288, 1997.

82. Hagman Z, Larne O, Edsjo A, et al: miR-34c is downregulated in prostate cancer and exerts tumor suppressive functions. Int $\mathrm{J}$ Cancer 127: 2768-2776, 2010.

83. Fujita Y, Kojima K, Hamada N, et al: Effects of miR-34a on cell growth and chemoresistance in prostate cancer PC 3 cells. Biochem Biophys Res Commun 377: 114-119, 2008.

84. Leslie A, Carey F, Pratt N and Steele R: The colorectal adenomacarcinoma sequence. Br J Surg 89: 845-860, 2002

85. Zhang X, Kim J, Ruthazer R, et al: The HBP1 transcriptional repressor participates in RAS-induced premature senescence. Mol Cell Biol 26: 8252-8266, 2006.

86. Toyota M, Suzuki H, Sasaki Y, et al: Epigenetic silencing of microRNA-34b/c and B-cell translocation gene 4 is associated with $\mathrm{CpG}$ island methylation in colorectal cancer. Cancer Res 68: 4123-4133, 2008

87. Suzuki H, Yamamoto E, Nojima M, et al: Methylation-associated silencing of microRNA-34b/c in gastric cancer and its involvement in an epigenetic field defect. Carcinogenesis 31: 2066-2073, 2010.

88. Sawada K, Radjabi A, Shinomiya N, et al: c-Met overexpression is a prognostic factor in ovarian cancer and an effective target for inhibition of peritoneal dissemination and invasion. Cancer Res 67: 1670-1679, 2007.

89. Corney D, Hwang C, Matoso A, et al: Frequent downregulation of miR-34 family in human ovarian cancers. Clin Cancer Res 16 $1119-1128,2010$

90. Yan D, Zhou X, Chen X, et al: MicroRNA-34a inhibits uveal melanoma cell proliferation and migration through downregulation of c-Met. Invest Ophthalmol Vis Sci 50: 1559-1565, 2009.

91. Guessous F, Zhang Y, Kofman A, et al: microRNA-34a is tumor suppressive in brain tumors and glioma stem cells. Cell Cycle 9 : $1031-1036,2010$

92. Wei J, Song Y, Durinck S, et al: The MYCN oncogene is a direct target of miR-34a. Oncogene 27: 5204-5213, 2008.

93. Cole K, Attiyeh E, Mosse Y, et al: A functional screen identifies miR-34a as a candidate neuroblastoma tumor suppressor gene. Mol Cancer Res 6: 735-742, 2008.

94. Ichimura A, Ruike Y, Terasawa K, Shimizu K and Tsujimoto G: MicroRNA-34a inhibits cell proliferation by repressing mitogen-activated protein kinase kinase 1 during megakaryocytic differentiation of K562 cells. Mol Pharmacol 77: 1016-1024, 2010.

95. He X, He C, Xiongb J, et al: Functional elucidation of miR-34 in osteosarcoma cells and primary tumor samples. Biochem Biophys Res Commun 38: 35-40, 2009. 